\title{
Guidelines for Neurosurgery Training Program
}

\author{
Raj Kumar ${ }^{1}$ \\ A. K. Mahapatra \\ ${ }^{1}$ Ex-President, Neurological Surgeon's Society of India, Vice Chancellor, \\ Uttar Pradesh University of Medical Sciences, Saifai, Etawah, \\ Uttar Pradesh \\ ${ }^{2}$ Director (Medical), Sum Hospital, Bhubaneshwar, Orissa \\ Indian J Neurosurg 2018;7:81-89
}

\section{Background}

Training in super specialty such as neurosurgery in our country is very heterogeneous. The quality of training and even the pattern of examination vary from corporate hospitals (for Diplomate of National Board [DNB]) and medical colleges to higher institutions. The clinical exposure, type of surgical skills, teaching methods, and decision making vary from expert to expert and from institution to institution. It is the responsibility of the national regulatory bodies and professional societies to set guidelines and monitor training of neurosurgery trainees to produce optimally trained experts who serve the society and nation with acceptable risk.

The Neurological Surgeons' Society of India (NSSI) is a responsible society of India, which is working intensively for the welfare of neurosurgery, citizens, and trainees. The NSSI organizes different standard courses for trainees across the country from time to time and tries to upgrade the deteriorating training standards all over the country to produce optimally trained experts to deal with the neurosurgical ailments.

\section{Aim}

The aim of the NSSI is to ascertain the following for trainees:

- Broad knowledge base of neurosurgery including basic neuroanatomy, neurophysiology neuroradiology, neurology, neuro-ophthalmology, and neurochemistry up to the level of decision making in a particular scenario

- Ensuring the clinical training up to an optimum level

- Neurosurgery operative skill and experiences

- Decision making in various clinical scenarios

- Analysis of self-results to improve trainees' knowledge in practice

\section{Duration of Training}

It remains 3 years following specialization (in general surgery) and 6 years following graduation in medical sciences. The training in clinical neurosurgery should be from a nationally accredited program. In case of 6 years of training, 2 years may be spent in surgical disciplines, whereas for 1 year they may be rotated in concerned specialties, that is, neuroradiology, neuropathology, neurology, neuropediatrics, neurobiology and neurophysiology, etc. In both the cases, 3 years should be available for clinical neurosurgery.

\section{Contents}

Training should be composed of:

- Basics of neurosurgery.

- Complete neurologic investigations.

- Neurologic procedures and tests.

- Clinical, radiologic, and final diagnosis; indications of investigations and surgery in neurosurgical conditions; operative and conservative treatment; operative position of procedures; anticipated complications and their management; and prognostications of neurosurgical cases. The follow-up protocol and investigations should also be understood by trainees.

- Surgical and conservative management of spine/spinal cord injuries and head injuries and basics of peripheral nerve injuries.

- Exposure to neurosurgical procedures with skill development.

- Desirable: neuroendoscopic procedures, neuronavigation procedures, minimally invasive neurosurgical procedures, electrophysiologic monitoring.

- Exposure to computed tomography (CT), magnetic resonance imaging (MRI), cerebral angiography, Doppler, tomography.

- Academic program

In case file:

- Daily clinical rounds with discussion on clinical cases on each working day.

- Clinical case writing with provisional diagnosis, clinicalradiologic diagnosis, laboratory report, and final diagnosis

(C2018 Neurological Surgeons'

License terms

Society of India 
after operative procedure following histopathology report as applicable.

- Preoperative preparations.

- Preoperative consent.

- Operative procedural planning.

- Intraoperative detailed findings, daily progress (frequency depending on severity).

- Filling of histopathology form with relevant operative / clinical notes.

- Postoperative course, treatment, observation, physical and neurologic progress, and information to relatives.

- Complications and their management.

- Minimum: Maintaining a logbook with time-to-time signature of head of department (HOD).

- Minimum seminars (20), journals clubs (15).

- Minimum mortality and morbidity presentations in form of clinical audit (20).

- Minimum clinical case presentations (30 cases).

- Minimum one dissertation, desirable three (two clinical and one experimental).

- Training of scientific writings with basic statistical concepts.

- Training of ethical issues.

- Resuscitation procedures.

\section{Training Program}

A written curriculum of training with contents and objectives of each year should be made for a structured training plan.

- Clinical duties, operation roster, emergency duties, timing of studies, and responsibilities should also be clearly laid down during training.

- Each rotation to concerned specialties and subspecialties should have clear guidelines, goals, and responsibilities with designated trainer and his/her contribution for trainee.

The first-year resident ( 3 year' trainees) should learn the clinical workup of cases; observe the general layout and working of the OT, understand the importance of maintaining sanctity of the OT, scrubbing, working, and sterilization of all the OT instrument; and understand the use of microscopes and micro-instruments. He/she is responsible for shifting of OT patients, for participating in surgery as second assistant, and for postoperative management of patients in recovery and in ward. The second-year resident is responsible for preoperative workup of the patient, surgical planning, and understanding the rationale of surgery. $\mathrm{He} /$ she is the first assistant in surgery and is responsible for anticipating intra- and postoperative complications and management. The final-year resident should be able to perform minor/medium/major surgeries independently and assist in medium/major/extra major surgeries. He/she should be able to handle emergencies and postoperative complications independently and is responsible for supervision and guidance of his/her juniors. By the time of appearing in examination, he should be able to make a decision in a particular clinical scenario.

\section{Medicolegal Responsibilities of Residents}

- All residents are given education regarding medicolegal responsibilities at the time of admission in a short workshop.

- They must be aware of the formalities and steps involved in making the correct death certificates, mortuary slips, medicolegal entries, requisition for autopsy, etc.

- They should be fully aware of the ethical angle of their responsibilities and should learn how to take legally valid consent for different hospital procedures and therapies. They should ensure confidentiality at every stage.

\section{Cases}

- Exposure of 350 to 400 cases at least for the whole training program (at the rate of 300 cases performed per OT in a year)

- At least two OTs a week (average) including trauma

- With around one-third cranial and one-third spinal

- At least $10 \%$ supervised/performed independently (at least 30 craniotomies)

- Spectrum: Neurotrauma, neuro-oncology, stroke, and cerebrovascular, pediatric, spinal

- If any of the above specialties are not available, trainees may be posted in other centers and trials should be made to develop at least three of these within 8 to 10 years of starting training in such institutes.

\section{Hierarchy}

Three/6 years (tentative).

First/second year: Lumbar puncture, external ventricular drainage (EVD), tracheostomy, intubation, emergency, scalp suturing, simple neuro trauma: chronic subdural, extradural hematoma, learning elective cases exposures, ventriculoperitoneal (VP) shunts (under supervision)

Second/third to fourth year: Neurotrauma: contusions, intracerebral hemorrhage (ICH). Elective cases exposures, all craniotomies, spine exposures

Third/fifth to sixth year: Subspecialty exposure depending on available subspecialties, elective exposures

\section{Independent Surgery (Supervised)}

Neurotrauma: Chronic subdural hematoma (CSDH), epidural hematoma, depressed fracture, contusions, ICH (experience with conventional craniotomy required).

Elective: VP shunts (always supervised), gliomas, lumbar disc/cervical disc.

\section{Internal Assessment of Operative Skills}

Once in 6 months.

Case performed under supervision and graded by a faculty (different faculty every time)

- Preoperative assessment

- Surgical planning 
- Exposure

- Surgical techniques and brain handling, if possible in operating theater

- Hemostasis

\section{Training Program}

- There should be a documented education program with lectures, clinical presentations, neuropathlogic and neuroradiologic conferences, a journal club, a morbidity and mortality presentation, teaching club, teaching, meetings including subspecialties, and teaching in medical ethics, administration, management, and economics.

- It is recommended that trainees participate at least once a year in a national training course, in a hands-on course or a national neurosurgical meeting, respectively.

- Each trainee must keep an authorized logbook for documentation of his/her operative experience. The trainee will have to demonstrate that he/she has assisted in a wide range of cases, which should include a balance of trainer-assisted and personal cases under supervision. The logbook must be supervised and signed regularly by the respective trainer and once in 6 months by HOD, and it must be available at national board examination/ Mch exit examination.

- Trainees should be encouraged to participate in research and to develop an understanding of research methodology. In academic programs, clinical and/or basic research opportunities must be available to trainees with appropriate faculty supervision.

\section{Training Institution}

A training institution must have national recognition in accordance with the standards of the NSSI training charter. Units that cannot comply with the minimum standards of the NSSI training charter (case volume and mixture, number of trainers and beds, etc. as listed below) and cannot offer the full spectrum of neurosurgery should not be allowed to be a training institution for neurosurgery.

\section{Requirements for Training Institutions Regarding Equipment and Educational Facilities}

- There must be a referral base sufficient to provide an adequate case volume and mixture to support training program.

- There must be a minimum of four trainers (including head of department) as per guidelines at MCI or DNB.

- There must be at least 20 neurosurgical beds and a separate high-dependency unit or preferably a separate intensive care unit (ICU) of at least 8 beds.

- There must be at least two designated, fully staffed operating theaters (neurosurgical trained staff), appropriately equipped and with 24-hour availability.

- There must be an operating microscope in each theater. The following (other than routine and microsurgical instruments) are essential equipment: ultrasonic aspirator, microsurgical drill, image guidance and/or ultrasound, radiologic imaging, and endoscopy equipment.

- Neurosurgical theaters should be covered by anesthetists with a special interest/training in neuroanesthesia. Anesthesia coverage should be available at all times for neurosurgery.

- Neurosurgical intensive care may be managed by neurosurgery, or there may be joint responsibility between neurosurgery and anesthesia.

- There must be an emergency unit with 24-hour admission.

- There must be exposure to pediatric neurosurgery as a mandatory component of a training program.

- There should be opportunity to obtain experience in functional neurosurgery and traumatic brain and spine injuries either within the department or in another neurosurgical department specializing in this field.

- All main specialties (neurology, surgery/traumatology, anesthesiology, radiology, neuroradiology, neuropathology, radiotherapy, internal medicine, pediatrics) must be present to provide the trainee with the opportunity of developing his/her skills in a team approach to patient care. There should be a separate neuro-rehabilitation unit to take care of patients in vegetative and crippling stage, and it should be taken care by physiotherapists and trained nurses.

- There should be an easily accessible library, with an adequate selection of books and journals on neurosurgery, as well as facilities for computer literature searches.

\section{Institutions Quality Management Provisions}

A training institution must have an internal system of quality assurance. There should be written guidelines concerning patient care and patient information (patient's consent), referrals, medical records, documentation, on-call and backup schedules, days off, residents working schedules, attendance at conference, and educational activities.

\section{Responsibilities of Head of Department/Head of Institute}

Responsibilities of HOD are the following:

- Organize and coordinate a balanced training program with established rotations ensuring that the trainee will have exposure to all aspects of neurosurgery. The program should be written and available to trainees and trainers.

- Ensure that there is dedicated time allocated to trainers for training and that trainers fulfill their training responsibilities.

- Ensure that there is dedicated time for trainees to attend educational meetings and approved courses and that trainees can fulfill all training obligations.

- Ensure that a trainee's documentation (training portfolio) is up to date and signed.

- Organize a transparent and fair annual progress evaluation of trainees, which must be communicated to them. 
- Ensure that trainees get adequate exposure in a particular subspecialty (functional epilepsy, cerebrovascular, skull base, spine) for a period of 3 months at another national/international center, if not available in the same center.

\section{Responsibilities of Trainers}

Trainers should be certified neurosurgeons and possess the necessary administrative, teaching and clinical skills, and commitment to instruct and support their trainees. They have to:

- Set realistic aims and objectives for a rotation period.

- Supervise the day-to-day work of the trainee on the ward, in the outpatient clinic, and in the operating room.

- Support trainees' operative and clinical progress and provide feedback.

- Assess and report on trainees' progress at the end of each rotation (progress evaluation).

\section{Requirements for Trainees}

- Trainees during their training should be exposed to at least three different trainers and the various spectrum of neurosurgical procedures.

- There should be an attached operative list (-Table 1) with summaries and optimal number of key procedures that trainees should have performed on completion of training. In addition to this mandatory list of operative procedures, the trainee should have assisted in or partly performed operations for pituitary adenomas, complex basal meningiomas, aneurysms, arteriovenous malformations (AVMs), acoustic neurinomas, pediatric procedures, intramedullary tumors, etc. (see assistant figures in - Table 1).

- Trainees should be directly involved in the pre- and postoperative management of these patients and should have a detailed understanding of the preoperative investigations.

Table 1 Neurosurgical procedure's training requirement-adults

\begin{tabular}{|c|c|c|c|c|}
\hline \multicolumn{5}{|c|}{ Operative totals } \\
\hline & & & Minimum & Optimum \\
\hline \multirow[t]{7}{*}{1} & Head injuries & Total & 125 & 235 \\
\hline & External ventricular drainage/ICP monitoring/reservoir & & 30 & 50 \\
\hline & Chronic subdural hematoma & & 20 & 40 \\
\hline & Craniotomy: extradural/subdural/intracerebral hematoma/contusions & & 50 & 100 \\
\hline & Depressed skull fracture & & 15 & 25 \\
\hline & Dural repair (CSF fistula) & & 5 & 10 \\
\hline & Cranioplasty & & 5 & 10 \\
\hline \multirow[t]{4}{*}{2} & Supratentorial tumors and lesions (excluding stereotactic procedure) & Total & 40 & 61 \\
\hline & $\begin{array}{l}\text { Intrinsic tumors: primary/metastatic } \\
\text { Meningioma }\end{array}$ & & $\begin{array}{l}30 \\
8\end{array}$ & $\begin{array}{l}40 \\
12\end{array}$ \\
\hline & Pituitary adenoma (trans-sphenoidal/transcranial) & & 0 & $5^{a}$ \\
\hline & Other benign lesions (epidermoid, arachnoidal cyst, etc.) & & 2 & 4 \\
\hline \multirow[t]{4}{*}{3} & Posterior fossa lesions & Total & 7 & 14 \\
\hline & Primary and metastatic tumors & & 3 & 6 \\
\hline & Chiari malformation/posterior fossa decompression & & 2 & 4 \\
\hline & Other benign lesions (epidermoid, arachnoidal cyst, von Hippel-Lindau, etc.) & & 2 & 4 \\
\hline \multirow[t]{2}{*}{4} & Infection (cranial/spinal) & Total & 8 & 12 \\
\hline & Abscess/subdural empyema & & 8 & 12 \\
\hline \multirow[t]{5}{*}{5} & Vascular & Total & 10 & 27 \\
\hline & Craniotomy: aneurysm & & 0 & $8^{\mathrm{a}}$ \\
\hline & Craniotomy: AVMs & & 0 & $2^{\mathrm{a}}$ \\
\hline & Cavernous angioma & & 0 & 3 \\
\hline & Hematoma (spontaneous intracerebral/intracerebellar) & & 8 & 12 \\
\hline \multirow[t]{2}{*}{6} & Hydrocephalus (> 16 y) & Total & 57 & 99 \\
\hline & Shunting procedure, initial & & 30 & 50 \\
\hline
\end{tabular}


Table 1 (Continued) Neurosurgical procedure's training requirement-adults

\begin{tabular}{|c|c|c|c|c|}
\hline \multicolumn{5}{|c|}{ Operative totals } \\
\hline & & & Minimum & Optimum \\
\hline & Shunt revision & & 15 & 25 \\
\hline & Endoscopic fenestrations & & 2 & 4 \\
\hline & External ventricular drainage & & 10 & 20 \\
\hline \multirow[t]{10}{*}{7} & Spine & Total & 155 & 240 \\
\hline & Cervical disc disease/spondylosis: anterior decompression/foraminotomy & & 15 & 25 \\
\hline & Cervical instrumentation (anterior/posterior) & & 20 & 30 \\
\hline & Lumbar disc disease/spondylosis: lumbar disc & & 50 & 70 \\
\hline & Laminotomy/laminectomy for spondylosis & & 20 & 30 \\
\hline & Lumbar instrumentation & & 15 & 25 \\
\hline & Spinal tumors: extradural & & 10 & 15 \\
\hline & Spinal tumors: intradural extramedullary & & 15 & 25 \\
\hline & Spinal tumors: instrumentation in vertebral tumors & & 0 & $5^{\mathrm{a}}$ \\
\hline & Spinal trauma: decompression/instrumentation & & 10 & 15 \\
\hline \multirow[t]{3}{*}{8} & Trigeminal and other neuralgias & Total & 2 & 10 \\
\hline & Injection techniques/radiofrequency lesion & & 0 & 5 \\
\hline & Microvascular decompression & & 2 & 5 \\
\hline \multirow[t]{5}{*}{9} & Stereotactic and functional neurosurgery & Total & 0 & 10 \\
\hline & Stereotactic tumor biopsy & & 0 & 5 \\
\hline & Surgery for epilepsy & & 0 & $3^{\text {a }}$ \\
\hline & Therapeutic electrostimulation (peripheral nerve, spinal) & & 0 & $2^{\mathrm{a}}$ \\
\hline & Implantation of ports/pumps for intrathecal drug delivery & & 0 & $3^{\mathrm{a}}$ \\
\hline \multirow[t]{2}{*}{10} & Peripheral nerve & Total & 5 & 10 \\
\hline & Entrapment decompression/transposition & & 5 & 10 \\
\hline \multirow[t]{3}{*}{11} & Basic techniques & Total & & \\
\hline & Craniotomy supratentorial & & 60 & 80 \\
\hline & Craniotomy/craniectomies posterior fossa & & 15 & 25 \\
\hline
\end{tabular}

Abbreviations: AVMs, arteriovenous malformations; CSF, cerebrospinal fluid; ICP, intracranial pressure.

It is of great importance that within the specific areas, there is sufficient experience. If the minimum of one key procedure is not fully met, it can be counterbalanced by a comparable key procedure of the same area. The minimum operative total of each area should be attained.

aFor some operations only "optimum" figures are given. A national society may redefine such operations as key procedures from time to time.

- Many of the above procedures demand the use of the operating microscope that the trainee must be fully familiar with.

- Trainees must maintain an operative logbook detailing their involvement in all cases. They should ensure that the goals and objectives of each rotation are met, that all problems are discussed with the assigned trainer, and that copies of the progress evaluation forms are stored. Also, it is recommended that they keep a record of courses attended, publications, and/ or presentations.

- A neurosurgical training record (-Table 2) lists the cumulative operative experiences done by a trainee and shows the "competence level" of each procedure expected at the end of training. On completion of training, trainees tabulate their cumulative operative totals and indicate their level of competence. The training head certifies an adequate competency level for each procedure by signing the training record.

- Trainees must work for 2 to 3 weeks in skill laboratory.

\section{Periodic Progress Evaluation}

Periodic evaluation at yearly intervals or at the end of a rotation period is an objective and fair instrument to ensure that trainees progressed satisfactorily throughout the training. The logbook is used as supporting documentation. The trainer produces a written summary, using a structured format (trainee Evaluation form), and discusses with the trainee whether: 
Table 2 Neurosurgical training requirements-pediatric through 15 years of age

\begin{tabular}{|c|c|c|c|c|}
\hline \multirow[t]{5}{*}{1} & \multirow{5}{*}{$\begin{array}{l}\text { Hydrocephalus and congenital malformation } \\
\text { External ventricular drainage } \\
\text { Shunting procedure }\end{array}$} & \multirow[t]{5}{*}{ Total } & \multicolumn{2}{|c|}{ Operative totals } \\
\hline & & & Minimum & Optimum \\
\hline & & & 50 & 90 \\
\hline & & & 15 & 30 \\
\hline & & & 35 & 60 \\
\hline \multirow[t]{4}{*}{2} & \multirow{4}{*}{$\begin{array}{l}\text { Head and spine injuries } \\
\text { Burr holes: ICP monitoring/drainage/reservoir } \\
\text { Chronic subdural hematoma/hygroma } \\
\text { Extradural/subdural hematomas }\end{array}$} & \multirow[t]{4}{*}{ Total } & 6 & 15 \\
\hline & & & 2 & 5 \\
\hline & & & 2 & 5 \\
\hline & & & 2 & 5 \\
\hline \multirow[t]{2}{*}{3} & \multirow{2}{*}{$\begin{array}{l}\text { Brain tumors and lesions } \\
\text { Supratentorial tumors }\end{array}$} & \multirow[t]{2}{*}{ Total } & 4 & 10 \\
\hline & & & 4 & 10 \\
\hline
\end{tabular}

Abbreviation: ICP, intracranial pressure.

For some operations only, "optimum" figures are given; the national society may redefine such operations as key procedures from time to time.

- Agreed goals have been met during the past rotation.

- Specific knowledge, operative totals, and all other aspects of training have been reached.

- Weak areas have been identified that require intensified supervision, advice, and training support. Failure to meet the agreed target must be brought to the attention of HOD/higher academic/training authority.

In addition, the further development of training should be discussed, and aims and objectives for the next rotation may be formulated. The evaluation sheet must be signed by the trainer/head and trainee and kept in the trainee's portfolio.

In future, a separate (anonymous) evaluation of their training by the trainees may become helpful to receive the feedback of the trainees concerning clinical and operative training, teaching, supervision and support, feedback of progress, and career advice.

- Trainees must be member of Indian society in neurosurgery.

- Trainees must attend conference and present paper, poster, etc.

- Trainees should write one to three papers.

\section{Key Procedures}

Every trainee at the end of training should be able to perform these procedures independently, that is, with a trainer supervising but not making a significant decision/practical manoeuver during the operation. The list is detailed and ensures that a trainee has acquired broad operative exposure ( - Table 1). With these key procedures, a certain standard of training is guaranteed and in future will become more and more important as subspecialty areas are developed.

Neurosurgical society may wish to include additional key procedures/aspects from time to time according to need.

\section{Minimum and Optimum Figures}

It is of great importance that within the specific categories, the trainee acquires sufficient experience. If the minimum of one key procedure is not fully met, this can be counterbalanced by a comparable key procedure of the same area. The minimum operative total for each area should be attained.

The optimum figures are provided as a goal for a good training program and also to allow for competency-based training. It takes into account that trainees progress at varying rates. For some operations, only "optimum" figures are indicated. National society may redefine such operations as key procedures.

If minimum figures are not achieved, smaller departments may need to arrange a rotation of their trainees for part of their training with larger departments with much better facilities.

\section{Assistant Figures}

- For many years, opinions among trainers have differed considerably as to whether each trainee should perform complex operations personally, such as aneurysms, AVMs, acoustic neuromas, spinal intramedullary tumors, basal meningiomas, brain tumors in children, etc. To solve this problem, a separate list of assistant figures is included (-Table 3, assistant figures). This list contains procedures that trainees have to assist in or perform in part but with no obligation to perform them personally/independently. Most of these procedures will be learned either after finishing residency or in a subsequent subspecialty program. The requirement of the assistant figures ensures that trainees are exposed to such complex diseases during their training and become familiar with diagnostic procedures, treatment options, and the follow-up required. The specified minimum figures should be attained. 
Table 3 Neurosurgical training requirements-assistant figures

\begin{tabular}{|l|l|}
\hline Procedure & Number \\
\hline Craniopharyngioma & 5 \\
\hline Pituitary adenomas (transsphenoidal + transcranial) & 10 \\
\hline Acoustic neurinoma & 10 \\
\hline Complex basal/posterior fossa meningioma & 10 \\
\hline Craniotomy: aneurysm & 12 \\
\hline Craniotomy: arteriovenous malformation (AVM) & 5 \\
\hline Occlusive: endarterectomy (optional) & 3 \\
\hline Thoracic disc disease & 3 \\
\hline Spinal tumors: intramedullary & 3 \\
\hline Thalamotomy, pallidotomy/stimulation technique (optional) & 5 \\
\hline Implantation of ports/pumps for intrathecal drug delivery (optional) & 5 \\
\hline Single-suture craniosynostosis & 2 \\
\hline Pediatric infratentorial tumors & 2 \\
\hline Meningocele/meningomyelocele & 15 \\
\hline Tethered cord syndromes & 5 \\
\hline Spinal dysraphism & 10 \\
\hline Peripheral nerve sutures (with graft, optional) & 3 \\
\hline
\end{tabular}

\section{Neurosurgical training record}

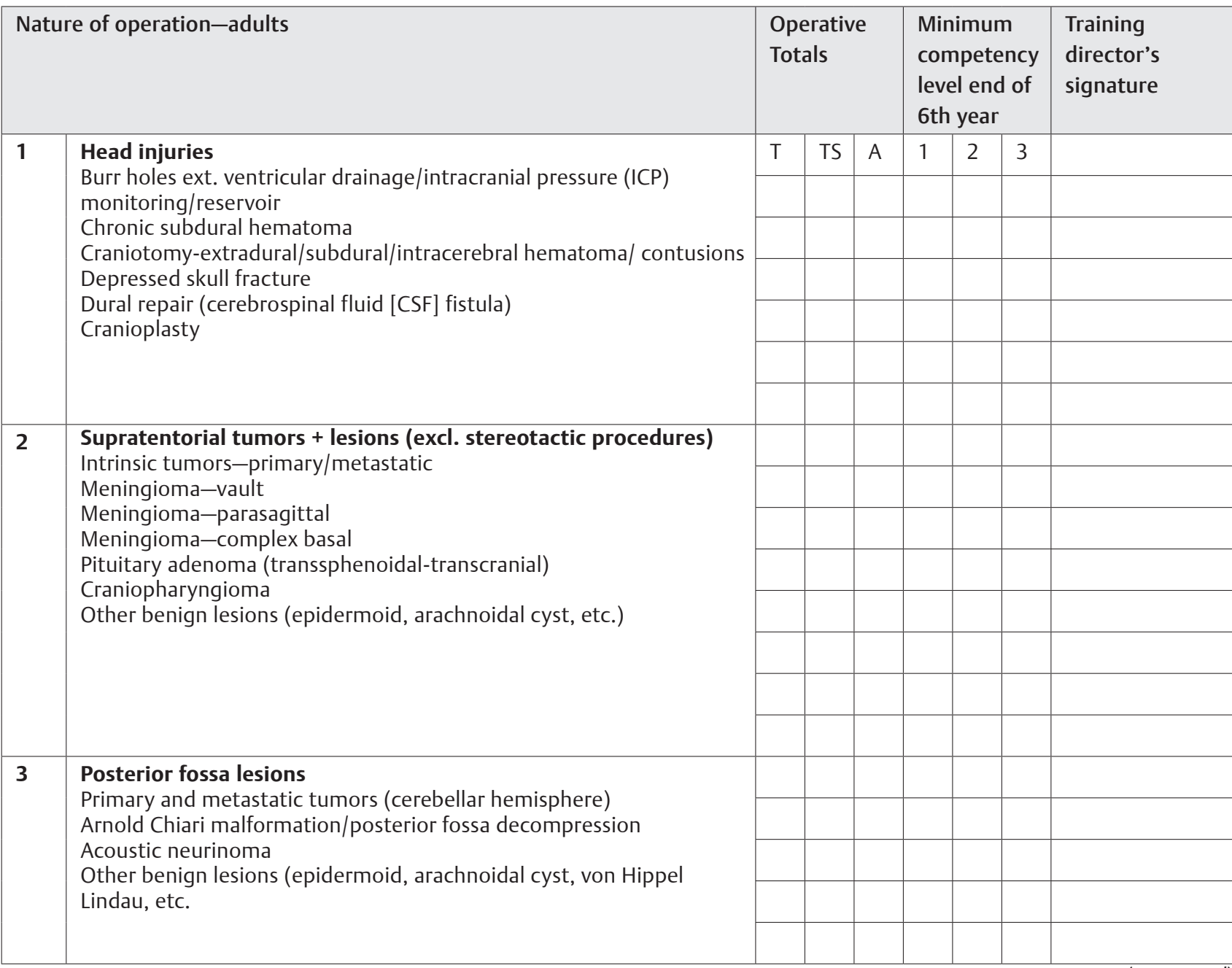


(Continued) Neurosurgical training record

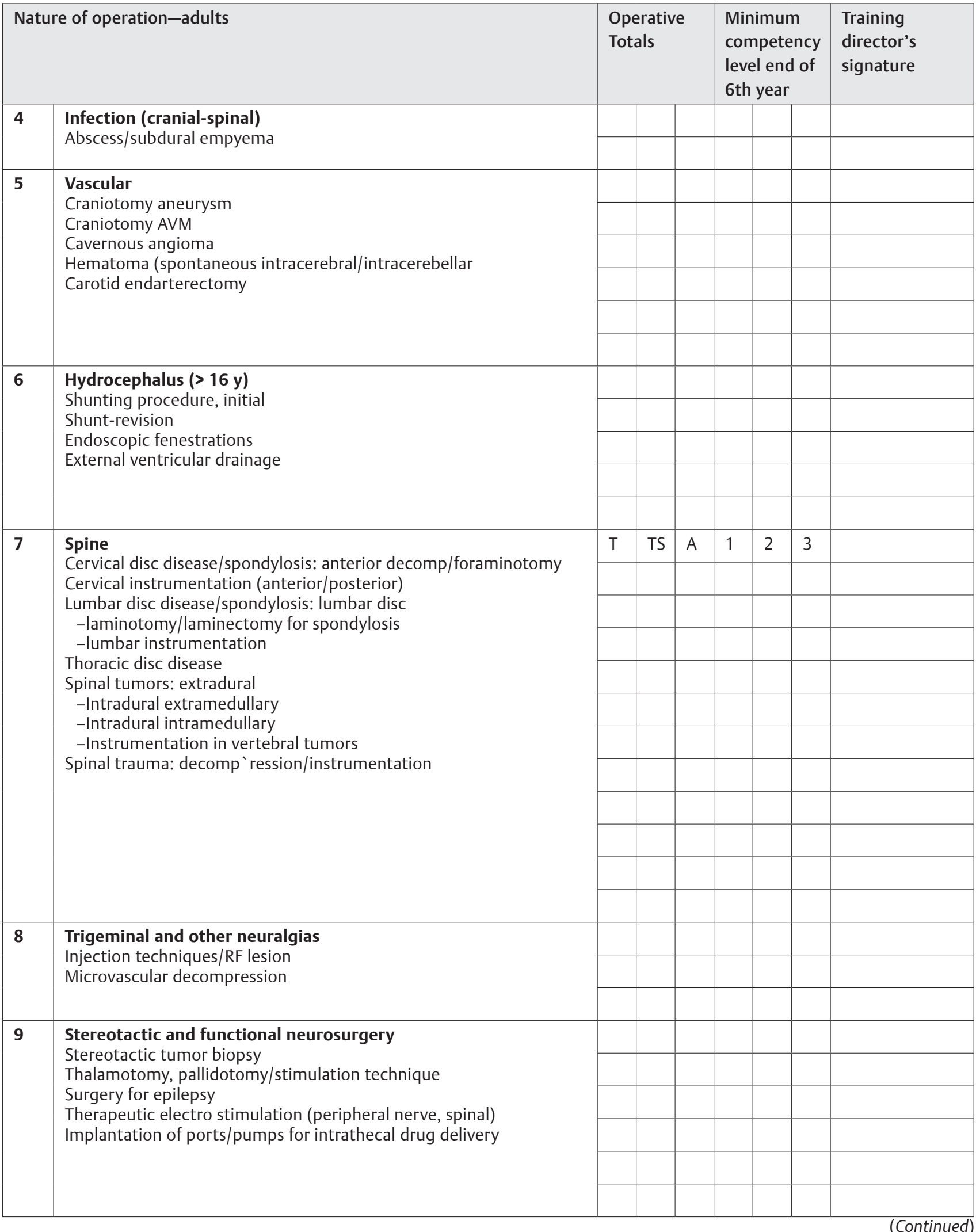


(Continued) Neurosurgical training record

\begin{tabular}{|c|c|c|c|c|}
\hline \multicolumn{2}{|c|}{ Nature of operation-adults } & $\begin{array}{l}\text { Operative } \\
\text { Totals }\end{array}$ & $\begin{array}{l}\text { Minimum } \\
\text { competency } \\
\text { level end of } \\
6 \text { th year }\end{array}$ & \multirow[t]{2}{*}{$\begin{array}{l}\text { Training } \\
\text { director's } \\
\text { signature }\end{array}$} \\
\hline 10 & Peripheral nerve & & & \\
\hline & Peripheral nerve sutures (with graft) & & & \\
\hline \multirow[t]{4}{*}{11} & \multirow{4}{*}{$\begin{array}{l}\text { Basic techniques } \\
\text { Craniotomy supratentorial } \\
\text { Craniotomy posterior fossa } \\
\text { Transsphenoidal approach }\end{array}$} & & & \\
\hline & & & & \\
\hline & & & & \\
\hline & & & & \\
\hline
\end{tabular}

Definitions

$T=$ The trainee has done the operation under guidance of trainer.

$\mathrm{TS}=$ The trainee has done the operation but the supervising consultant has made a significant decision/practical manoeuver during the operation.

$\mathrm{C}=$ The trainee has performed component parts during the operation under supervision of a senior surgeon: positioning, operative approach

(i.e., craniotomy, opening) closure, drainage, draping, instructions for postoperative care.

$\mathrm{A}=$ The trainee is the principal assistant during the operation.

Competency levels

$1=$ Should have assisted in, but is unable to perform the procedure

2 = Competent to perform procedure under direct supervision

3 = Competent to perform procedure without direct supervision

\begin{tabular}{|c|c|c|c|c|c|c|c|c|}
\hline \multicolumn{2}{|r|}{ Operative totals-pediatric through 15 y } & \multicolumn{3}{|c|}{$\begin{array}{l}\text { Operative } \\
\text { totals }\end{array}$} & \multicolumn{3}{|c|}{$\begin{array}{l}\text { Minimum } \\
\text { competency level } \\
\text { end of } 6 \text { th year }\end{array}$} & \multirow[t]{2}{*}{$\begin{array}{l}\text { Training director's } \\
\text { signature }\end{array}$} \\
\hline \multirow[t]{4}{*}{1} & \multirow{4}{*}{$\begin{array}{l}\text { Hydrocephalus and congenital malformation } \\
\text { External ventricular drainage } \\
\text { Shunting procedure } \\
\text { Meningomyelocele } \\
\text { Tethering syndromes } \\
\text { Spinal dysraphism }\end{array}$} & $\mathrm{T}$ & TS & $A+C$ & 1 & 2 & 3 & \\
\hline & & & & & & & & \\
\hline & & & & & & & & \\
\hline & & & & & & & & \\
\hline & & & & & & & & \\
\hline \multirow[t]{3}{*}{2} & \multirow{3}{*}{$\begin{array}{l}\text { Head and spine injuries } \\
\text { Burr holes, ICP monitoring/drainage/reservoir } \\
\text { Chronic subdural hematoma/hygroma } \\
\text { Extra-/subdural hematoma }\end{array}$} & & & & & & & \\
\hline & & & & & & & & \\
\hline & & & & & & & & \\
\hline \multirow[t]{2}{*}{3} & \multirow{2}{*}{$\begin{array}{l}\text { Supra- and/or infratentorial tumors and lesions } \\
\text { Supratentorial and/or infratentorial tumors }\end{array}$} & & & & & & & \\
\hline & & & & & & & & \\
\hline
\end{tabular}

Definitions

$\mathrm{T}=$ The trainee has done the operation under the guidance of supervisor.

TS $=$ The trainee has done the operation but the supervising consultant has made a significant decision/practical manoeuver during the operation.

$\mathrm{C}=$ The trainee has performed component parts during the operation under supervision of a senior surgeon: positioning, operative approach

(i.e., craniotomy, opening) closure, drainage, draping, instructions for postoperative care.

$A=$ The trainee is the principal assistant during the operation.

Competency levels

$1=$ should have assisted in, but is unable to perform the procedure

2 = Competent to perform procedure under direct supervision

$3=$ Competent to perform procedure without direct supervision

\section{Acknowledgments}

These guidelines have been prepared with the help of European guidelines published in textbook of
"Neurosurgery". Authors acknowledge their great contribution with thanks. 